\title{
Clustering Algorithms of Wireless Sensor Networks: A Survey
}

\author{
Muhammad Noman Riaz ${ }^{\mathrm{a}}$ \\ ${ }^{a}$ Department of Computer Science, Virtual University of Pakistan, Lahore, 54000
}

Received: 23 April 2018; Accepted: 25 May 2018; Published: 08 July 2018

\begin{abstract}
In the recent few years the research on Wireless Sensor Networks (WSN) and its variants have risen enormously. The researchers all across the globe are trying to develop a routing protocol that is energy efficient and provides adequate security level in data communication. One of the techniques the researchers use is Clustering of the sensor network. This technique inherently consumes less energy during data communication as the nodes have assigned a dedicated task to perform. A total of 35 clustering algorithms / protocols have been surveyed and comparison of these protocols based on the metrics like heterogeneity, clustering method, size of the cluster etc. have been presented.
\end{abstract}

Index Terms: Network lifetime, cluster size, cluster count, residual energy, node degree, average network energy

(C) 2018 Published by MECS Publisher. Selection and/or peer review under responsibility of the Research Association of Modern Education and Computer Science

\section{Introduction}

The WSN organizes several sensing nodes that cooperate wirelessly among each other, are settled in threedimensional way to intelligently monitor and record and subsequently convey desired information on intended environmental / physical phenomenon. Fundamentally, a WSN is a group of wireless sensor nodes which has the ability of self-configuration, as per the requirements. A classic wireless sensor node comprises of four essential parts namely: a Sensor Module (that senses the environmental / physical phenomenon), a Memory \& Processing Module (an entity that processes the desired sensed data), a Transceiver Module (an entity that both receives and transmits the required data) and a Power Unit (that distributes and regulates the power requirements of the entire WSN node). The WSNs consume a substantial part in military owing to reconnaissance and surveillance requirements in very tough to reach territories. Also, the WSN technology has institute valuable usages in commercial, industrial, health and marine theater.

* Corresponding author. Tel.: +92-333-3083304

E-mail address: mnriaz@cae.nust.edu.pk 
The researchers over a period of time have proposed hundreds of energy efficient protocols based on different techniques. One of the techniques they utilized is Clustering. The clustering of sensor network is either take place soon after the deployment of sensor nodes in the target area or it takes place in the later stages of the deployment of the nodes. The sensor nodes in cluster based routing, present in the cluster elects its Cluster Head $(\mathrm{CH})$ and then the member nodes of the respective cluster disseminate their recorded data to Base Station (BS) via elected CHs. The technique of clustering ensures in prolonging network lifetime.

The paper is further structured in four sections as mentioned. The Section 2 describes related work, section 3 discussed the cluster based routing protocols, section 4 summarizes the discussion and conclusion is given in section 5 .

\section{Related Work}

A lot of researchers have contributed in the development of cluster based energy efficient routing protocols during the past ten years. Several survey papers have been published by the academicians and researchers. The authors of these survey papers have not discussed and compared a large of clustering protocols in their papers. Thereby unable to clearly draft a wholesome picture of clustering pros and cons in WSN architecture. Several authors have discussed the protocols and algorithms of WSN in detail but the authors have not compared a large number of protocols and algorithms in details.

Over a period of time a large number of protocols and algorithms of WSN have been developed and simulated but the main drawback lies with these protocols is that they are yet to be implemented or emulated on a physical platform to determine their energy efficiency. As the WSN sensor nodes are battery operated, the conservation of energy in these sensor nodes are of prime importance. Keeping in view this critical factor of energy consumption the authors have put in some efforts in writing the literature review of the existing protocols to compare them and evaluate them on the basis of their energy consumption. A short description of the related works is presented in Table 1 below:

Table 1. Related Work in Tabular Form

\begin{tabular}{|c|c|c|c|}
\hline Year & Authors & Literature & Main Contributions \\
\hline $2010[1]$ & Vivek Katiyar et al. & $\begin{array}{l}\text { "Clustering Algorithm for } \\
\text { Heterogeneous Wireless Sensor } \\
\text { Networks : A Survey" }\end{array}$ & - Discussion on 12 clustering protocols \\
\hline $2011[2]$ & $\begin{array}{l}\text { Vinay Kumar, Ganjeev } \\
\text { Jain, Sudarshan Tiwari }\end{array}$ & $\begin{array}{l}\text { "Energy Efficient Clustering } \\
\text { Algorithms in Wireless Sensor } \\
\text { Networks : A Survey" }\end{array}$ & $\begin{array}{l}\text { - Discussion on } 22 \text { clustering protocols and } \\
\text { different variants of LEACH } \\
\text { - Comparison of the protocols discussed }\end{array}$ \\
\hline $2012[3]$ & Dipak Wajgi et al. & $\begin{array}{l}\text { "Load Balancing Algorithms in } \\
\text { Wireless Sensor Networks" }\end{array}$ & $\begin{array}{l}\text { Discussion on } 13 \text { clustering protocols } \\
\text { - Comparison of the protocols discussed }\end{array}$ \\
\hline 2013[4] & D.J. Dechene et al. & $\begin{array}{l}\text { "A Survey of Clustering Algorithms } \\
\text { for Wireless Sensor Networks" }\end{array}$ & $\begin{array}{l}\text { - Discussion on } 12 \text { clustering protocols } \\
\text { - Division of Protocols in terms of } \\
\text { Heuristics, Hierarchical, Weighted and Grid } \\
\text { Schemes }\end{array}$ \\
\hline $2014[5]$ & B. Revathy et al. & $\begin{array}{c}\text { "Latest Algorithms in Wireless Sensor } \\
\text { Networks for Energy Conservation : } \\
\text { A Survey" }\end{array}$ & $\begin{array}{l}\text { - Discussion on } 03 \text { clustering protocols } \\
\text { - Pseudo code of the protocols were } \\
\text { elaborated }\end{array}$ \\
\hline $2015[6]$ & $\begin{array}{l}\text { Gaurav Kumar Nigam et } \\
\text { al. }\end{array}$ & $\begin{array}{c}\text { "A Survey on Protocols and Routing } \\
\text { Algorithms for Wireless Sensor } \\
\text { Networks" }\end{array}$ & $\begin{array}{l}\text { - Discussion on } 13 \text { clustering protocols } \\
\text { - Advantages \& disadvantages of each } \\
\text { protocol of each protocol were specifically } \\
\text { mentioned }\end{array}$ \\
\hline 2015[7] & Mohini Kumrawat et al. & $\begin{array}{l}\text { "Survey on Clustering Algorithms of } \\
\text { Wireless Sensor Networks" }\end{array}$ & $\begin{array}{l}\text { - Discussion on } 10 \text { clustering protocols } \\
\text { - Discussed protocols were divided on the } \\
\text { basis of connectivity, mobility, } \\
\text { identification and combined weight. }\end{array}$ \\
\hline
\end{tabular}




\section{Clustering Algorithms' \& Protocols For WSN}

The WSN algorithms and protocols can be categorized in several different ways. In this paper we have categorized the clustering algorithms / protocols of WSN on the basis of probabilistic and non-probabilistic protocols and are described below:

\section{A. Probabilistic Protocols}

In probability based clustered routing protocols each sensor node at the time of deployment is assigned with probability that how often that sensor node will likely to be selected as $\mathrm{CH}$ during the $\mathrm{CH}$ election process. The assigned probability of the senor node serves as the basic criterion for $\mathrm{CH}$ selection.

The WSN algorithms and protocols are described below:

\section{Low Energy Adaptive Cluster Hierarchical (LEACH) Protocol}

The authors in [8] proposed a well-known cluster centered routing protocol known as Low Energy Adaptive Cluster Hierarchical (LEACH) routing protocol. In LEACH after every round the energy level of the current Cluster Head $(\mathrm{CH})$ is checked and if its energy is drained and below the threshold value then based on the probabilistic theory new $\mathrm{CH}$ will be selected. The responsibilities of the $\mathrm{CH}$ are to be rotated or shared among the sensor nodes of the network. This rotation of $\mathrm{CH}$ responsibility stabilizes the consumption of energy of network nodes such that no node will be overwhelmed.

\section{Stable Election Protocol (SEP)}

The authors in [9] introduced a clustering algorithm and named it Stable Election Protocol (SEP). In SEP, the authors have introduced heterogeneity i.e. "Normal Nodes" and "Advanced Nodes" (nodes that have more initial energy when deployed) are present in sensor network. Only "Advanced Nodes" are capable of performing their duties as $\mathrm{CHs}$ while the Normal Nodes can either be as relay nodes or for transmission of its own data but cannot perform the function of data aggregation as it is specific for CHs. The $\mathrm{CH}$ selection is centered on the remaining energy of the sensor nodes. The global knowledge of residual energy of the sensing nodes is not necessary to select the $\mathrm{CH}$ after every round.

\section{Hybrid Energy Efficient Distributed Computing (HEED) Protocol}

The authors in [10], in order to increase the balance of energy consumption among different parts of the sensor network, have utilized remaining or residual energy, degree of node or node density as a main parameters for the selection of $\mathrm{CH}$. The HEED protocol works on the three main parameters i.e. distribution of energy consumption for increasing the lifetime of the network, the selection of $\mathrm{CH}$ is to be terminated after a fixed or pre-defined number of iterations and thirdly the $\mathrm{CH}$ are spread or located in such a manner that maximum number of nodes have an easy access to them.

\section{Distributed Energy Efficient Hierarchical Clustering (DWEHC) Protocol}

The researchers in [11] suggested energy efficient routing protocol which is weight centered and it is developed to ensure the energy efficiency by creating the clusters of balanced sized and improving intra cluster network topology. Every sensor node in the network computes its corresponding weight in the network by measuring its remaining energy as well as total number of directly connected neighbors. A node which has the highest weight in the neighborhood will be regarded as the $\mathrm{CH}$ and other nodes will become the member nodes. 
The "Member Nodes" at that time are termed as "First Level Member" nodes because they are situated at a single hop distance with the $\mathrm{CH}$. The member nodes try to reach or communicate with the $\mathrm{CH}$ by consuming less amount of energy. Actually member node can accomplish by consulting with their neighboring nodes the path after following which the least amount of energy would likely to be consumed. This protocol has a drawback that it has a very unreliable or stability period because a large quantity of energy is expended in neighbor finding process.

\section{Distributed Energy Efficient Clustering (DEEC) Algorithm}

The authors in [12] developed a routing protocol that is multilevel clustering protocol explicitly engineered for heterogeneous WSNs. In the protocol a procedure for the selection of $\mathrm{CH}$ is established on the ratio of remaining energy of the sensor node which is being evaluated for the role of $\mathrm{CH}$ with that of the average network energy. In this protocol the authors have initially considered two levels of energy i.e. the sensor nodes distributed in network are of two energy levels or possess different amounts of energy. Later on, a generic solution for multi-level energy level solution was figured out. Each node of the network must have knowledge of energy levels of all sensor nodes present in the sensing network. This protocol forms the varying number of clusters after each round of $\mathrm{CH}$ selection.

\section{Distributed Energy Balance Clustering (DEBC) Protocol}

The authors in [13] proposed a clustering protocol similar to the DEEC protocol in that the selection of $\mathrm{CH}$ in each round is based on the residual energy of the sensor node that is being evaluated for the next round $\mathrm{CH}$ with that of the average energy of the remaining node of the network. The nodes of different energy levels are deployed randomly in target area and the nodes that have the higher initial energy will likely to be selected as $\mathrm{CH}$ number of times than their low energy counter parts nodes. This protocol increases the capability of existing classical LEACH and SEP protocols by employing two energy level heterogeneity.

\section{An Unequal Cluster-Based Routing (UCR) Protocol}

The authors of [14] proposed this protocol in order to mitigate the issue of hot spot in the sensor networks. This protocol is reactive or source driven routing protocol specifically designed for applications such as environmental monitoring, fire detection etc. The selection of $\mathrm{CH}$ is centered on the remaining energy of the neighboring sensor nodes. The CHs which are located near the BS have less quantity of nodes in their cluster as compare to the $\mathrm{CHs}$ that are situated farther from the BS. Therefore, the CHs near from the BS consume less energy in the transmission of data to BS believe to devote that saved energy for the relaying of inter cluster traffic. The $\mathrm{CHs}$ selection and clusters formation are accomplished in two phases that consumes a lot of energy. Furthermore, the cluster size is not same of all the clusters.

\section{Cluster Based Service Discovery (C4SD) Protocol}

The authors in [15] have proposed a protocol in which each node of the network is assigned with a unique hardware ID and a numerical weight value. The node which has the highest level of capability must be assigned a task of $\mathrm{CH}$. Such nodes perform the role of service directory for registration of nodes in the cluster. This protocol ensures the less amount of maintenance overhead and construction overhead incur during the section process of $\mathrm{CH}$. The sensor nodes react quickly to any topological changes occurred in the network by utilizing the information available from the nodes that are only 1-hop away and it evades the chain reaction. 
The authors in [16] proposed a routing protocol that splits the larger clusters into smaller clusters to save a significant amount of energy incurred due to nodes redundancy. This has been achieved by using the sub cluster head mechanism. This mechanism lead to fact the $\mathrm{CHs}$ will be receiving data frames of small sizes and a large number of data frames will be received by the BS during that particular period of time. Furthermore, only one of the redundant node is active and communicating with other nodes while the other nodes are in sleep mode and will remain in sleep mode till the time the active node gets exhausted and its energy level depleted. Hence, this mechanism will lead to increased network lifetime.

\section{Energy Efficient Heterogeneous Cluster (EEHC) Protocol}

The authors in [17] have proposed a routing protocol in which the sensing nodes of three dissimilar energy levels are deployed randomly in the intended area. An election process of $\mathrm{CH}$ is centered on the weighted probability assigned to each sensor node of network. In this protocol the Member Nodes of the cluster connect with corresponding $\mathrm{CH}$ and then $\mathrm{CHs}$ of each cluster will transmit or communicate the aggregated data to the BS.

\section{Stochastic Distributed Energy Efficient Clustering (SDEEC) Protocol}

The researchers in [18] proposed an application specific clustering protocol that is basically the extension of DEEC protocol by implementing the stochastic approach to save energy by reducing the intra cluster transmission. This approach is useful once the intent is to get the max or min data values such as pressure, humidity, and temperature etc. from the target area of the deployed network. The $\mathrm{CH}$ chooses only the relevant information from the entire range of received data from the nodes and subsequently disseminates that selected data to the BS. In this way the nodes that have a critical information to share with its corresponding $\mathrm{CH}$ can only remain active while the nodes that do not have something significant to share must be I sleep mode. Thereby a huge amount of energy will be saved and network will likely to experience less communication interference and low or no traffic congestion.

\section{Stochastic and Balanced Distributed Energy Efficient Clustering (SBDEEC) Protocol}

The author is [19] proposed a clustering protocol with the purpose of decreasing energy consumption and increase the lifetime of network. The protocol helps in deploying the sensor nodes of two different energy levels. During the initial rounds of the $\mathrm{CH}$ selection the sensor nodes with the higher energy level are more likely to be selected as $\mathrm{CHs}$ and when the residual energy of these $\mathrm{CHs}$ becomes approximately equal to that of the nodes with initial lower energy levels are now become at parity and have identical probability to be selected as CHs. This protocol also reduces the intra cluster communication overhead especially when the aim is to acquire max or min data values such as pressure, temperature etc.

\section{Distributed Cluster Head Election (DCHE) Protocol}

The authors in [20] suggested a cluster centered routing protocol for heterogeneous WSNs. The sensor nodes of three different energy levels are deployed in the sensor network and individual node of the network is allotted with a unique weight of probability to be elected as CH. In this protocol the "Member Nodes" of each cluster link with respective $\mathrm{CH}$ and then the $\mathrm{CHs}$ will communicate the aggregated data to $\mathrm{BS}$. A node having highest current weighted value will be chosen as $\mathrm{CH}$ for that particular round. The simulation results obtained in [21] depict that the performance of DHCE is far better than DEEC and LEACH routing protocols.

Temporary-DEEC 
The authors in [21] developed a protocol that is multilevel clustering protocol explicitly designed for heterogeneous WSNs. In this protocol, a procedure for the selection of $\mathrm{CH}$ is established on the ratio of remaining energy of the sensor node which is being evaluated for the role of $\mathrm{CH}$ with that of the average network energy. In this protocol the authors have initially considered two levels of energy and three levels i.e. the nodes distributed in the sensor network are of two / three energy levels or possess different amounts of energy. Later on, a generic solution for multi-level energy level solution was figured out. Each node of the network must have knowledge of energy levels of all the nodes present in sensor network. For $\mathrm{CH}$ select the average network energy is required that is inherently more energy consuming. This protocol forms the varying number of clusters after each round of $\mathrm{CH}$ selection.

\section{Developed Distributed Energy Efficient Clustering (DDEEC) Protocol}

The authors in [22] have suggested a clustering protocol that is basically founded on DEEC protocol. In that protocol, the nodes of the sensor network must have a global knowledge of the network nodes. Each node uses its initial energy and the residual energy during the $\mathrm{CH}$ election process. The sensor node having the highest amount of present energy will be chosen as the $\mathrm{CH}$ for that round. The ideal value of the lifetime of the network must be calculated because this value will be used as a reference value for the communicating nodes that what amount of energy these expend for the data transmission. Each member node of the cluster send the recorded data of its environment to the $\mathrm{CH}$ and the $\mathrm{CH}$ after performing data aggregation send that aggregated data to the BS.

\section{Energy Efficient Clustering for Self-Organized (EECS) Protocol}

The authors in [23] proposed an energy efficient clustering protocol based on three parameters. The election of $\mathrm{CH}$ for each round is based on the weighted probability assigned to each node in the initial phase of the network. As mentioned earlier the $\mathrm{CH}$ is elected for each round by considering the three parameters. Firstly, the amount of energy the node under evaluation for the role of $\mathrm{CH}$ presently possesses i.e. the difference between the initial energy and the energy depleted. Secondly, the amount of time the nodes takes to be selected as the $\mathrm{CH}$ and the time it takes to aggregate the received data and send it to the BS and thirdly the number of times the node selected as $\mathrm{CCH}$ in the past. In this way the issue of decreasing residual energy has been resolved. However, a large amount of time is consumed in the election process of the $\mathrm{CH}$ and the clusters of different sizes are created in the area of interest.

\section{Mobile Node based Clustering Protocol (MNCP)}

The authors in [24] proposed an algorithm that resolves the problem hot spot or energy hole created due to low residual energy of the sensor nodes. In this protocol the authors demonstrated that the mobile node can move anywhere in the network where the nodes are facing difficulty in the $\mathrm{CH}$ election process due to low residual energy of the competing sensor nodes. Whenever a node facing a problem in $\mathrm{CH}$ election process due to low residual energy level it sends a message intended for an active mobile node in the nearby area. The nearby mobile node will quickly respond to the message and move towards the intended area in order to rescue that residual energy node. So, the energy of the nodes will be utilized in a more balanced manner and consequently the network lifetime will be increased.

\section{Improved and Balanced LEACH Protocol}

The authors in [25] proposed a self-organizing and adaptive clustering routing protocol for the heterogeneous wireless sensor networks. This protocol achieves the balanced energy consumption by using randomization technique in even distribution of workload among the sensor nodes. In this protocol the high energy nodes 
which are often known as NCG nodes takes the responsibilities of the $\mathrm{CH}$ and starts aggregating the data received form the cluster's member nodes and after the process of data fusion send that fused data to the chosen gateway nodes to further transmission to the faraway BS. Hence, fused data transmission responsibility has been shifted to the gateways and CHs energy can be saved significantly.

\section{Energy Consumption \& Lifetime analysis in Clustered Multi-hop (ECLCM) Protocol}

The authors in [26] proposed an algorithm that estimates the energy consumption in multi hop wireless senor network with each node having a predefined probability for $\mathrm{CH}$ selection. In this protocol each node selected itself as a $\mathrm{CH}$ with the probability defined initially and starts to inform its neighboring nodes or the nodes that are located in its transmission range. Each node receives a certain number of advertisement messages from the prospective $\mathrm{CHs}$ during a certain period of time and the node that node as their $\mathrm{CH}$ which is least number hops away from it. In case if more than one sensor nodes are at the same least number of hops away then the node will randomly pick one of these nodes as its $\mathrm{CH}$. This process will go on till the time each node present in the network either selected its $\mathrm{CH}$ or itself becomes a $\mathrm{CH}$. As for data communication the TDMA approach is used by the sensor nodes the chance of data collision is much less. The Multihop environment may create network holes near the BS.

\section{Weighted Election Protocol (WEP)}

The authors in [27] have proposed a routing algorithm that enhances the stability period of the network. In this protocol the weight to each node of the sensor network is assigned to the extent that each node has equal opportunity to be selected as $\mathrm{CH}$. While assigning the weight to each node of the network it is to ensure that weight must be equal to the initial energy of the node to that of the initial energy of the normal nodes deployed in the sensor networks. After the assignment of probability weights to each node of the network the cluster numbers are assigned and the CHs are selected in the same manner as selected in case of LEACH protocol. After that the CHs chain is to be built and hence the chain leader is to be selected in a random fashion. The member nodes of the clusters send their recorded data to their respective $\mathrm{CHs}$ and these $\mathrm{CHs}$ after data fusion send the fused data to the BS.

\section{Energy Efficient Cluster Based Data Aggregation (EECBDA) Protocol}

The authors in [28] suggested an energy efficient protocol to increase the lifetime and stability period of the network. During the cluster formation phase of the EECBDA protocol a group of clusters are established in the sensor network. A Layer in the network must have ' $n$ ' number of clusters i.e. individual layer is additionally distributed into ' $n$ ' number of clusters. For the duration of the $\mathrm{CH}$ election process every individual sensor node is to be elected from each of the layers based on the current amount of remaining energy and Communication Cost Factor (CCF). When the sensor node is chosen as the $\mathrm{CH}$ then it broadcasts the advertisement message to all nodes of the cluster, $\mathrm{CHs}$ of different layers and the BS. As this protocol is using TDMA approach for data communication then each node sends its sensed data to its respective $\mathrm{CH}$ during the allotted time and $\mathrm{CH}$ then sends the fused data to the BS. The $\mathrm{CH}$ utilizes the intermediate nodes in transmitting the data to the BS. The redundant data packets will be removed during the data aggregation process at the $\mathrm{CH}$. In the Maintenance phase of the protocol, the residual energy of each sensor node is checked and if the residual energy is less than the desired threshold energy level than the new $\mathrm{CH}$ is required to be elected from the same cluster for the next round.

\section{Density Control Energy Balanced Clustering (DCEBC) Protocol}


The authors in [29] proposed an energy efficient routing protocol that works by electing the $\mathrm{CH}$ on the basis of present energy level of the sensor nodes and the probability threshold value. The protocol also taken into account the identification of redundant nodes and their deactivation to avoid traffic congestion and save energy.

\section{Heterogeneous Sensor Network (HSR)}

The authors in [30] created a heterogeneous sensor network that have a small number high energy sensor nodes and a large number of low energy sensor nodes deployed randomly and uniformly in the target area. Hence, each sensor node is fully aware of its location in the network. The $\mathrm{CH}$ is elected based on the strength of the signal it sends to its potential cluster members. Finally, the $\mathrm{CH}$ sends the fused data to the BS via multiple hops situated in between $\mathrm{CH}$ and BS.

\section{Traffic Bases Clustering (TBC) Protocol}

The authors in [31] have proposed a cluster based routing protocol in which the topology of the network is adaptive. The network topology is dependent on the pattern of the traffic and the node density of the target area. The $\mathrm{CH}$ that is situated near the BS have to perform dual responsibilities both of sending the data collected from its own cluster members and the data received from other $\mathrm{CHs}$ that are not in the transmission range of the BS. Therefore, in this scenario the $\mathrm{CHs}$ that located nearer to the BS will be depleted soon than the $\mathrm{CHs}$ that are situated away from the BS. This leads to the failure of the network in totality. Also, the authors suggest that the network topology be developed in those regions where the node density is higher and hence the load balancing will be performed effectively.

\section{Probability Driven Unequal Clustering (PRODUCE) Protocol}

The authors in [32] proposed an algorithm that organizes the sensor network that has clusters of unequal sizes. The clusters which are away from the BS have greater number of sensor nodes than the clusters which are situated near the BS. To elect the $\mathrm{CH}$ different probability values are assigned in each level of the network.

\section{Energy and Distance Based Clustering (EDBC) Protocol}

The authors in [33] developed a protocol that considers the residual energy as well the distance of each sensor node with the BS in the $\mathrm{CH}$ election process. In a large network of sensor nodes some of the nodes are deployed near to the BS while other nodes are deployed far from the BS. The nodes that are deployed away from the BS high transmission power to send data to the BS. In order to avoid this the authors have divided the entire network area into concentric circular regions around the BS. The CHs in each of these segments are different and the $\mathrm{CHs}$ of circular segments which are situated near to the BS have higher probability of selecting as $\mathrm{CH}$ than those $\mathrm{CHs}$ that are situated away from the BS.

\section{Distributed Clustering with Load Balancing (DCLB) Protocol}

The authors in [34] proposed a distributed clustering algorithm that builds clusters of different sizes in every step depending on the load of the network. The volume of data that is required to be sent to the BS is to be measured in every step. The part of the network that has greater volume of data, a large number of clusters will be built there to share the data for the purpose of load balancing.

\section{Density and Distance Based Cluster Head Selection (DDCHS) Protocol}


The authors in [35] developed an algorithm in which the election of $\mathrm{CH}$ is based on the distance and density of sensors in the network. In the protocol the area of clustering is divided into four quadrants of equal sizes by drawing two perpendicular diameters. The $\mathrm{CH}$ from each quadrant is to be elected based on the node density and distance from the BS.

\section{Energy Efficient Clustering Scheme with Self-Organized ID Assignment (EECSIA)}

The authors in [36] developed an energy efficient cluster based routing protocol that considers both the network topology and current energy levels of the sensor nodes. The protocol makes the sensor network scalable by assigning unique Identification Number (ID) to each of the sensor nodes which helps in reducing the communication overhead and thereby increasing the network lifetime. Furthermore, the EECSIA routing protocol ensures that an energy of $\mathrm{CH}$ will not drain due to the reception of large amount of data from the common member sensor nodes by performing re-clustering locally in constant time frame.

\section{Fault Tolerant Energy Efficient Distributed Clustering (FEED) Protocol}

The authors in [37] proposed an energy efficient algorithm that uses four parameters namely density of the nodes in the network, current energy level of the sensor nodes, distance between the sensor nodes and the centrality of the nodes in the network. The authors have proposed a supervisory node that is to be nominated and placed in every cluster as a backup of $\mathrm{CH}$. In case of failure of $\mathrm{CH}$ the supervisory node will take over as a $\mathrm{CH}$ for that cluster. This characteristic will ensure the increment in network lifetime as well as the network will become more fault tolerant and robust. However, as the nodes require a global knowledge of the sensor nodes in the election of $\mathrm{CH}$ which is costly as nodes share their position with other nodes of the network.

\section{B. NON - PROBABILISTIC PROTOCOLS}

In non - probabilistic based clustered routing protocol the selection process is more specific depending on several factors such as connectivity of sensor nodes, position of the nodes, number of neighbouring nodes etc.

\section{Location Based Clustering (LBC) Algorithm}

The authors in [38] have proposed a routing protocol in which the clustering of the network will take place once in the lifetime of the network. The CHs are formed on the basis of the residual energy of the nodes present in a particular cluster. The rotation time for the change in $\mathrm{CH}$ is dependent on the type of application for the nodes are performing their duties as different application or type of data consumes different amount of energy while sending their recorded data to the intended destination nodes. Such an arrangement ensures the even consumption of energy which results in prolong lifetime of the network.

\section{Node Degree Based (NDB) Protocol}

The authors in [39] have proposed a routing protocol in which they deployed two types of sensor nodes i.e. Advanced Nodes and Normal Nodes. The Advanced Nodes have more energy than the Normal Nodes. The nodes having higher energy level i.e. Advanced Nodes are likely to be selected as CHs of their respective clusters. The degree with which they are located are also considered during their election process as CHs. The communication overhead for the election of $\mathrm{CH}$ has been reduced. 
The authors in [40] have proposed cluster based energy efficient routing protocol. The authors combined two well-known clustering protocols; LEACH and PEGASIS to get the optimum performance from their proposed protocol. In this protocol the BS is positioned in the center of the fan-shaped sensor network and the clusters that are away from the BS have more nodes density than the clusters which are near to the BS. This enables the $\mathrm{CHs}$ located near to the BS to conserve more energy as compare to their farther counterparts $\mathrm{CHs}$ and that preserved energy can further be utilized in intra-cluster communication. Therefore, the communication will become balanced and the network lifetime increases.

\section{Voting on Grid Clustering (VoGC)}

In [41] the authors have used the methods of voting and clustering to produce an energy efficient and secure localization of the sensor nodes. Instead of using conventional clustering method the authors have adopted Voting-On-Grid method to reduce computational cost.

\section{Battery Aware Reliable Clustering (BARC)}

In [42] the authors have proposed an energy efficient cluster based routing protocol in which the authors have used Z-MAC protocol for data communication and the $\mathrm{CH}$ rotates among the available active nodes as per the defined battery recovery schemes.

\section{Cluster Based Routing Protocols : A Comparison}

Below in Table 2 we have compared the above discussed routing protocols

Table 2. Comparison of WSN Algorithms \& Protocols

\begin{tabular}{|c|c|c|c|c|c|c|c|c|c|c|c|c|c|c|c|c|c|}
\hline \multirow{3}{*}{ 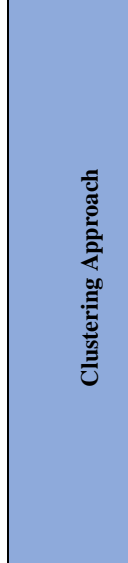 } & \multirow{3}{*}{ 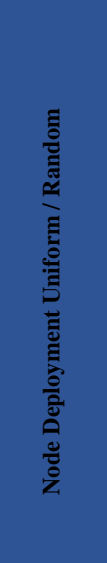 } & \multirow{3}{*}{ 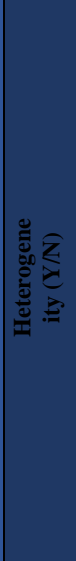 } & \multirow{3}{*}{ 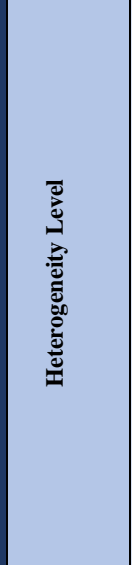 } & \multirow{3}{*}{ 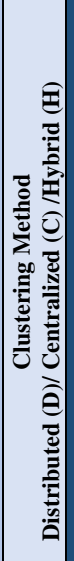 } & \multirow{3}{*}{ 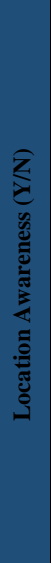 } & \multirow{3}{*}{ 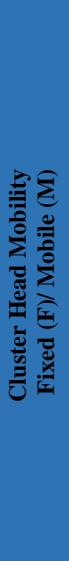 } & \multirow{2}{*}{\multicolumn{6}{|c|}{ 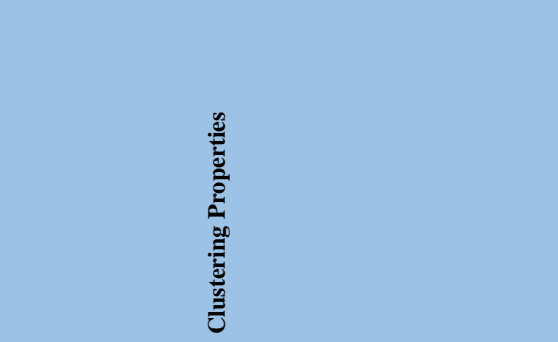 }} & \multicolumn{5}{|c|}{ 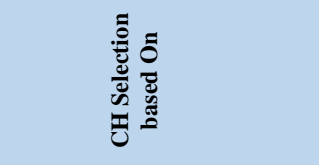 } \\
\hline & & & & & & & & & & & & & 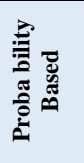 & & 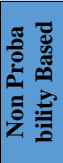 & & \\
\hline & & & & & & & 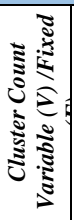 & 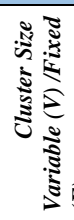 & 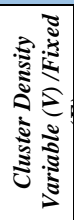 & 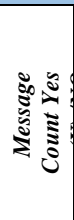 & 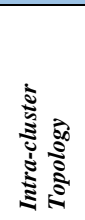 & 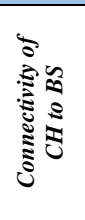 & 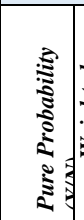 & 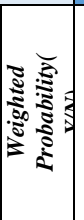 & 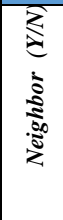 & 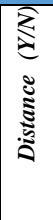 & 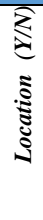 \\
\hline LEACH [9] & Random & $\mathrm{N}$ & - & $\mathrm{D}$ & $\mathrm{N}$ & F & V & V & V & $\mathrm{N}$ & $\begin{array}{l}\text { Single } \\
\text { Hop }\end{array}$ & $\begin{array}{l}\text { Direct } \\
\text { Link }\end{array}$ & Y & - & - & - & - \\
\hline SEP [10] & Random & $\mathrm{Y}$ & Two & $\mathrm{D}$ & $\mathrm{N}$ & F & V & $\mathrm{V}$ & V & $\mathrm{N}$ & $\begin{array}{c}\text { Single } \\
\text { Hop }\end{array}$ & $\begin{array}{l}\text { Direct } \\
\text { Link }\end{array}$ & - & $\mathrm{Y}$ & - & - & - \\
\hline HEED [11] & Random & $\mathrm{N}$ & - & $\mathrm{D}$ & $\mathrm{N}$ & $\mathrm{F}$ & V & $\mathrm{V}$ & V & $\mathrm{N}$ & $\begin{array}{c}\text { Single } \\
\text { Hop }\end{array}$ & $\begin{array}{l}\text { Direct } \\
\text { Link }\end{array}$ & $\mathrm{Y}$ & - & - & - & - \\
\hline $\begin{array}{l}\text { DWEHC } \\
{[12]}\end{array}$ & Random & $\mathrm{N}$ & - & $\mathrm{D}$ & $\mathrm{N}$ & F & V & $\mathrm{V}$ & V & $\mathrm{N}$ & $\begin{array}{l}\text { Single } \\
\text { Hop }\end{array}$ & $\begin{array}{l}\text { Direct } \\
\text { link }\end{array}$ & - & Y & - & - & - \\
\hline DEEC [13] & Random & Y & Two/ Multi & $\mathrm{D}$ & $\mathrm{N}$ & $\mathrm{F}$ & V & V & V & $\mathrm{N}$ & $\begin{array}{l}\text { Single } \\
\text { Hop }\end{array}$ & $\begin{array}{l}\text { Direct } \\
\text { Link }\end{array}$ & - & Y & - & - & - \\
\hline
\end{tabular}


Clustering Algorithms of Wireless Sensor Networks: A Survey

\begin{tabular}{|c|c|c|c|c|c|c|c|c|c|c|c|c|c|c|c|c|c|}
\hline DEBC [14] & Random & $\mathrm{Y}$ & Two/ Multi & $\mathrm{D}$ & $\mathrm{N}$ & F & V & $\mathrm{V}$ & V & $\mathrm{N}$ & $\begin{array}{l}\text { Single } \\
\text { Hop }\end{array}$ & $\begin{array}{l}\text { Direct } \\
\text { Link }\end{array}$ & - & Y & - & - & - \\
\hline UCR [15] & Random & $\mathrm{N}$ & - & D & $\mathrm{N}$ & F & V & V & V & $\mathrm{N}$ & $\begin{array}{l}\text { Single } \\
\text { Hop }\end{array}$ & $\begin{array}{l}\text { Multi } \\
\text { Hop }\end{array}$ & $\mathrm{Y}$ & $\mathrm{Y}$ & - & - & - \\
\hline C4SD [16] & Random & $\mathrm{Y}$ & Multi & $\mathrm{D}$ & $\mathrm{Y}$ & M & V & V & V & $\mathrm{N}$ & $\begin{array}{l}\text { Multi } \\
\text { Hop }\end{array}$ & $\begin{array}{l}\text { Multi } \\
\text { Hop }\end{array}$ & - & $\mathrm{Y}$ & - & - & - \\
\hline \begin{tabular}{|l|} 
Improved \\
LEACH \\
{$[17]$} \\
$17]$
\end{tabular} & Random & $\mathrm{N}$ & - & $\mathrm{D}$ & $\mathrm{N}$ & $\mathrm{F}$ & V & $\mathrm{V}$ & V & $\mathrm{N}$ & $\begin{array}{l}\text { Single } \\
\text { Hop }\end{array}$ & $\begin{array}{l}\text { Direct } \\
\text { Link }\end{array}$ & Y & - & - & - & - \\
\hline EEHC [18] & Random & Y & Three & D & $\mathrm{N}$ & $\mathrm{F}$ & V & V & V & $\mathrm{N}$ & $\begin{array}{l}\text { Single } \\
\text { Hop }\end{array}$ & $\begin{array}{l}\text { Direct } \\
\text { Link }\end{array}$ & - & $\mathrm{Y}$ & - & - & - \\
\hline SDEEC [19] & Random & Y & Two & $\mathrm{D}$ & $\mathrm{N}$ & F & V & $\mathrm{V}$ & V & $\mathrm{N}$ & $\begin{array}{c}\text { Single } \\
\text { hop }\end{array}$ & $\begin{array}{l}\text { Direct } \\
\text { Link }\end{array}$ & - & $\mathrm{Y}$ & - & - & - \\
\hline \begin{tabular}{|l} 
SBDEEC \\
{$[20]$}
\end{tabular} & Random & Y & Two & D & $\mathrm{N}$ & F & V & V & V & $\mathrm{N}$ & $\begin{array}{l}\text { Single } \\
\text { Hop }\end{array}$ & $\begin{array}{l}\text { Direct } \\
\text { Link }\end{array}$ & - & $\mathrm{Y}$ & - & - & - \\
\hline DCHE [21] & Uniform & Y & Three & $\mathrm{D}$ & $\mathrm{N}$ & F & v & v & F & $\mathrm{N}$ & $\begin{array}{l}\text { Single } \\
\text { Hop }\end{array}$ & $\begin{array}{l}\text { Direct } \\
\text { Link }\end{array}$ & - & $\mathrm{Y}$ & - & - & - \\
\hline TDEEC [22] & Random & Y & Two/ Multi & $\mathrm{D}$ & $\mathrm{N}$ & F & V & v & V & $\mathrm{N}$ & $\begin{array}{l}\text { Single } \\
\text { Hop }\end{array}$ & $\begin{array}{l}\text { Direct } \\
\text { Link }\end{array}$ & - & $\mathrm{Y}$ & - & - & - \\
\hline \begin{tabular}{|l} 
DDEEC \\
{$[23]$}
\end{tabular} & Random & Y & Two & $\mathrm{D}$ & $\mathrm{N}$ & F & V & V & V & $\mathrm{N}$ & $\begin{array}{l}\text { Single } \\
\text { Hop }\end{array}$ & $\begin{array}{l}\text { Direct } \\
\text { Link }\end{array}$ & - & $\mathrm{Y}$ & - & - & - \\
\hline EECS [24] & Random & $\mathrm{N}$ & - & $\mathrm{D}$ & $\mathrm{N}$ & F & V & V & V & $\mathrm{N}$ & $\begin{array}{l}\text { Single } \\
\text { Hop }\end{array}$ & $\begin{array}{l}\text { Direct } \\
\text { Link }\end{array}$ & - & $\mathrm{Y}$ & - & - & - \\
\hline MNCP [25] & Random & $\mathrm{N}$ & - & $\mathrm{D}$ & $\mathrm{N}$ & M & V & V & V & $\mathrm{N}$ & $\begin{array}{l}\text { Single } \\
\text { Hop }\end{array}$ & $\begin{array}{l}\text { Direct } \\
\text { Link }\end{array}$ & - & $\mathrm{Y}$ & - & - & - \\
\hline $\begin{array}{l}\text { IB-LEACH } \\
{[26]}\end{array}$ & Random & $\mathrm{N}$ & - & D & $\mathrm{N}$ & F & V & V & V & $\mathrm{N}$ & $\begin{array}{l}\text { Single } \\
\text { hop }\end{array}$ & $\begin{array}{l}\text { Direct } \\
\text { Link }\end{array}$ & Y & - & - & - & \\
\hline \begin{tabular}{|l} 
EECSIA \\
{$[27]$}
\end{tabular} & Random & $\mathrm{N}$ & - & D & $\mathrm{N}$ & $\mathrm{F}$ & $\mathrm{V}$ & V & V & $\mathrm{Y}$ & $\begin{array}{l}\text { Single } \\
\text { Hop }\end{array}$ & $\begin{array}{l}\text { Direct } \\
\text { Link }\end{array}$ & - & - & $\mathrm{Y}$ & - & - \\
\hline WEP [28] & Random & Y & Two & $\mathrm{D}$ & $\mathrm{N}$ & F & V & v & V & $\mathrm{N}$ & $\begin{array}{l}\text { Single } \\
\text { Hop }\end{array}$ & $\begin{array}{l}\text { Direct } \\
\text { Link }\end{array}$ & - & Y & - & - & - \\
\hline ECDBA[29] & Random & $\mathrm{N}$ & - & $\mathrm{D}$ & $\mathrm{N}$ & F & V & V & V & $\mathrm{Y}$ & $\begin{array}{l}\text { Single } \\
\text { Hop }\end{array}$ & $\begin{array}{l}\text { Direct } \\
\text { Link }\end{array}$ & - & - & $\mathrm{Y}$ & - & - \\
\hline DCEBC[30] & Random & Y & Two & $\mathrm{D}$ & $\mathrm{N}$ & F & V & V & V & $\mathrm{N}$ & $\begin{array}{l}\text { Single } \\
\text { Hop }\end{array}$ & $\begin{array}{l}\text { Direct } \\
\text { Link }\end{array}$ & - & Y & - & - & - \\
\hline HSR [31] & Random & Y & Two & D & $\mathrm{N}$ & F & V & v & V & $\mathrm{N}$ & $\begin{array}{l}\text { Single } \\
\text { Hop }\end{array}$ & $\begin{array}{l}\text { Direct } \\
\text { Link }\end{array}$ & - & Y & - & - & - \\
\hline TBC [32] & Random & Y & Two & $\mathrm{D}$ & $\mathrm{N}$ & F & V & V & V & $\mathrm{N}$ & $\begin{array}{l}\text { Single } \\
\text { Hop }\end{array}$ & $\begin{array}{l}\text { Direct } \\
\text { Link }\end{array}$ & - & Y & - & - & - \\
\hline $\begin{array}{l}\text { PRODUCE[ } \\
33]\end{array}$ & Random & $\mathrm{Y}$ & Two & $\mathrm{D}$ & $\mathrm{N}$ & $\mathrm{F}$ & V & V & V & $\mathrm{N}$ & $\begin{array}{l}\text { Single } \\
\text { Hop }\end{array}$ & $\begin{array}{l}\text { Direct } \\
\text { Link }\end{array}$ & - & $\mathrm{Y}$ & - & - & - \\
\hline EDBC[34] & Random & Y & Two & $\mathrm{D}$ & $\mathrm{N}$ & F & V & V & V & $\mathrm{N}$ & $\begin{array}{l}\text { Single } \\
\text { Hop }\end{array}$ & $\begin{array}{l}\text { Direct } \\
\text { Link }\end{array}$ & - & Y & - & - & - \\
\hline DCLB[35] & Random & $\mathrm{Y}$ & Two & $\mathrm{D}$ & $\mathrm{N}$ & $\mathrm{F}$ & V & V & V & $\mathrm{N}$ & $\begin{array}{l}\text { Single } \\
\text { Hop }\end{array}$ & $\begin{array}{l}\text { Direct } \\
\text { Link }\end{array}$ & - & $\mathrm{Y}$ & - & - & - \\
\hline DDCHS[36] & Random & $\mathrm{Y}$ & Two & $\mathrm{D}$ & $\mathrm{N}$ & F & V & V & $\mathrm{V}$ & $\mathrm{N}$ & $\begin{array}{l}\text { Single } \\
\text { Hop }\end{array}$ & $\begin{array}{l}\text { Direct } \\
\text { Link }\end{array}$ & - & Y & - & - & - \\
\hline EECSIA[37] & Random & Y & Two & $\mathrm{D}$ & $\mathrm{N}$ & $\mathrm{F}$ & V & V & V & $\mathrm{N}$ & $\begin{array}{l}\text { Single } \\
\text { Hop }\end{array}$ & $\begin{array}{l}\text { Direct } \\
\text { Link }\end{array}$ & - & $\mathrm{Y}$ & - & - & - \\
\hline FEED[38] & Random & Y & Two & $\mathrm{D}$ & $\mathrm{N}$ & $\mathrm{F}$ & V & v & V & $\mathrm{N}$ & $\begin{array}{l}\text { Single } \\
\text { Hop }\end{array}$ & $\begin{array}{l}\text { Direct } \\
\text { Link }\end{array}$ & - & Y & - & - & - \\
\hline LBC[39] & Random & $\mathrm{N}$ & - & $\mathrm{C}$ & $\mathrm{Y}$ & F & F & $\mathrm{F}$ & $\mathrm{V}$ & Y & $\begin{array}{l}\text { Single } \\
\text { Hop }\end{array}$ & $\begin{array}{l}\text { Direct } \\
\text { Link }\end{array}$ & - & $\mathrm{Y}$ & - & - & $\mathrm{Y}$ \\
\hline NDBC [40] & Random & $\mathrm{Y}$ & Two & $\mathrm{D}$ & $\mathrm{N}$ & F & F & V & V & Y & $\begin{array}{l}\text { Multi } \\
\text { Hop }\end{array}$ & $\begin{array}{l}\text { Single } \\
\text { Hop }\end{array}$ & - & - & $\mathrm{Y}$ & - & - \\
\hline PEZCA[41] & Random & $\mathrm{Y}$ & Two & $\mathrm{D}$ & $\mathrm{N}$ & F & V & V & V & $\mathrm{N}$ & $\begin{array}{l}\text { Single } \\
\text { Hop }\end{array}$ & $\begin{array}{l}\text { Single } \\
\text { Hop }\end{array}$ & - & Y & $\mathrm{Y}$ & - & - \\
\hline VoGC[42] & Random & Y & Two & $\mathrm{D}$ & $\mathrm{N}$ & F & F & V & V & Y & $\begin{array}{l}\text { Multi } \\
\text { Hop }\end{array}$ & $\begin{array}{l}\text { Single } \\
\text { Hop }\end{array}$ & - & - & $\mathrm{Y}$ & - & - \\
\hline BARC[43] & Random & Y & Two & $\mathrm{D}$ & $\mathrm{N}$ & F & V & V & V & $\mathrm{N}$ & $\begin{array}{c}\text { Single } \\
\text { Hop }\end{array}$ & $\begin{array}{c}\text { Single } \\
\text { Hop }\end{array}$ & - & Y & $\mathrm{Y}$ & - & - \\
\hline
\end{tabular}




\section{Conclusions \& Future Work}

The energy efficiency of WSN is of critical importance as the sensor are using low energy batteries and usually deployed in hostile environment[44]. We have surveyed 35 clustering algorithms in which the authors have used metrics like node density, residual energy, node degree, average energy of the network etc. in the election process of $\mathrm{CH}$ which ensures consumption of fewer amounts on node energy in totality. However, some of these protocols lead in the formation of variable cluster sizes and variable cluster counts and some of the protocols create a hole near the BS which then consumes more energy in message communication as the nodes will have to take longer route to reach the BS. As far as the future work is concerned more existing protocols will be compared and simulated to determine their actual energy consumption in different sensing environments. The comparison and simulation of large number of existing WSN routing protocols and algorithms will assist the researchers in developing more energy robust and efficient routing protocols and algorithms.

\section{References}

[1] Vivek Katiyar, Narottam Chand, Surender Soni, "Clustering Algorithm for Heterogeneous Wireless Sensor Networks : A Survey", International Journal of Wireless and Mobile Netwroks, 2010.

[2] Vinay Kumar, Ganjeev Jain, Sudarshan Tiwari, "Energy Efficient Clustering Algorithms in Wireless Sensor Networks: A Survey”, International Journal of Scientific \& Engineering Research, 2011.

[3] Dipak Wajgi, Dr. Nileshsingh V. Thakkur, "Load BalancingAlgorithms in Wireless Sensor Networks", International Journal of Computer \& Wireless Communication,Vol 2, No4, August 2012.

[4] D.J. Dechene, A. El Jardali, A. Sauer, "A Survey of Clustering Algorithms for Wireless Sensor Networks", International Journal of Computer \& Wireless Communication, Vol 4, No2, Decemebr, 2013.

[5] B. Revathy, G.Rekha, "Latest Algorithms in Wireless Sensor Networks for Energy Conservation A Survey”, International Journal of Engineering Research \& Technology, Vol 3 , Issue 10, October 2014.

[6] Gaurav Kumar Nigam, Chetna Dabas, "A Survey on Protocols and Routing Algorithm for Wireless Sensor Networks", Proceedings of the World Congress on Engineering and Computer Science, Vol 2, 201

[7] Mohini Kumrawat, Manoj Dhawan, "Survey on Clustering Algorithms of Wireless Sensor Networks", International Journal of Computer Science \& Information Technologies, Vol 6(3), 2015.

[8] W. Rabiner Heinzelman and H. Balakrishnan, 2000. Energy-Efficient communication Protocol for Wireless microsensor networks, IEEE, Proceeding of the 3rd Hawali International Conference on System Science.

[9] W. Heinzelman, A. Chandrakasan, and H. Balakrishnan, 2002. An application specific protocol architecture for wireless microsensor networks, IEEE Transactions on Wireless Communications.

[10] I.F. Akyildiz et al., Wireless sensor networks: a survey, Computer Network.

[11] Georgios Smaragdakis and Ibrahim Matta, 2004. SEP: A Stable Election Protocol for Clustered Heterogeneous Wireless Sensor Networks., 2012.

[12] O. Younis, S. Fahmy, "HEED: A Hybrid, Energy-Efficient, Distributed clustering approach for Ad Hoc sensor networks, IEEE Transactions on Mobile Computing, 2004.

[13] P. Ding, J. Holliday,. A. Celik, Distributed energy efficient hierarchical clustering for wireless sensor networks, In: Proceedings of the IEEE International Conference on Distributed Computing in Sensor Systems (DCOSS'05), 2005.

[14] Xiaojiang Du and Fenging Lin,. Designing Efficient Routing Protocol for Heterogeneous Sensor Network, IEEE, Performance, Computing and Communication conference, 2005.

[15] L. Qing, Q. Zhu, M. Wang,. Design of a distributed energy-efficient clustering algorithm for heterogeneous wireless sensor networks, In ELSEVIER, Computer Communications, 2006. 
[16] A.A. Abbasi and M. Younis,. A survey on clustering algorithms for wireless sensor network, Computer Communication, 2007.

[17] Guihai Chen - Chengfa Li,. An unequal cluster-based routing protocol in wireless sensor networks, Springer Science Business Media, LLC, 2007.

[18] R.S. Marin-Perianu and J. Scholten,. Cluster-based service discovery for heterogeneous wireless sensor networks, International Journal of Parallel, Emergent and Distributed Systems, 2007.

[19] Vijay Kr. Chaurasiya and S. Rahul Kumar,. Traffic Based Clustering in Wireless Sensor Network, IEEE WCSN, 2008.

[20] Mehdi Saeidmanesh and Mojtaba Hajimohammadi,. Energy and Distance Based Clustering: An Energy Efficient Clustering Method for Wireless Sensor Networks, World Academy of Science, Engineering and Technology, 2009.

[21] Farruh Ishmanov and Sung Won Kim,. Distributed Clustering Algorithm with Load Balancing in Wireless Sensor Network, IEEE World Congress on Computer Science and Information Engineening,2009.

[22] Chong Wang and Jiakang Liu,. An Improved LEACH Protocol for Application Specific Wireless Sensor Networks, IEEE Conference on Communication Engineering, 2010.

[23] B. Elbhiri and R. Saadane,. Stochastic Distributed Energy-Efficent Clustering (SDEEC) for heterogeneous wireless sensor networks, 2009.

[24] Elbhiri Brahim and Saadane Rachid,. Stochastic and Balanced DistributedEnergy-Efficient Clustering (SBDEEC) for heterogeneous wireless sensor networks, Signal Processing and communications group $U P C, 2009$.

[25] Dilip Kumar and Trilok C., “ Distributed Cluster Head Election (DCHE) Scheme for Improving Lifetime of Heterogeneous Sensor Networks", Tamkang Journal of Science and Engineering,2010.

[26] Parul Saini, Ajay K Sharma,“ Energy Efficient Scheme for Clustering Protocol Prolonging the Lifetime of Heterogeneous Wireless Sensor Networks”, International Journal of Computer Applications,2010.

[27] Kyounghwa Lee and Hyeopgeon Lee. "A Density and Distance based Cluster Head Selection Algorithm in Sensor Networks, IEEE, ICACT, 2010.

[28] Kyung Tae Kim and Han Ku Yoo, “. EECS: An Energy Efficient Cluster Scheme In Wireless Sensor Networks, IEEE International Conference on Computer and Information Technology, 2010.

[29] Babar Nazir and Halabi Hasbullah,". Mobile Nodes based Clustering Protocol for Lifetime Optimization in Wireless Sensor Network, In: International Conference on Intelligent and Information Technology, 2010.

[30] Ben Alla Said and EZZATI Abdellah,. Improved and Balanced LEACH for Heterogeneous Wireless Sensor Networks, 2010.

[31] Qingchao Zheng, . "An Energy Efficient Clustering Scheme with Self-Organized ID

[32] Assignment for Wireless Sensor Networks", Parallel and Distributed Systems , 2010.

[33] Mehrani, M., “ FEED: Fault tolerant, energy efficient, distributed Clustering forWSN, IEEE, ,2010.

[34] Jinhua Choi and Chaewoo Lee, "Energy consumption and lifetime analysis in clustered multi-hop wireless sensor networks using the probabilistic cluster-head selection method", EURASIP Journal on Wireless Communications and Networking, 2011.

[35] Md. Golam Rashed and M. Hasnat Kabir, "WEP: an Energy Efficient Protocol for Cluster Based Heterogeneous Wireless Sensor Network", International Journal of Distributed and Parallel Systems (IJDPS), 2011.

[36] Ashok Kumar and Narottam Chand, “ Location Based Clustering in Wireless Sensor Network”, World Academy of Science, Engineering and Technology,2011.

[37] F Bai,H. Mu and J. Sun "Power Efficient Zoning Clustering Algorithm for Wireless Sensor Networks". In the proceedings of the Information Engineering and Computer Science, 1-4, 2011.

[38] W.Yang and W. T. Zhu "Voting- o n Grid Clustering for source localization in Wireless Sensor Networks", in the proceedings of International Conference on Communication, 1 -5, 2014. 
[39] K. Wafta, O. Mirza and J. Kawtharani, "BARC: A Battery Aware Reliable Clustering Algorithm for Wireless Sensor Networks", Journal of Computer Networks and Applications, 32,6, 1183-1193, 2014

[40] F Bai,H. Mu and J. Sun "Power Efficient Zoning Clustering Algorithm for Wireless Sensor Networks". In the proceedings of the Information Engineering and Computer Science, 1-4.

[41] W .Yang and W. T. Zhu "Voting -on Grid Clustering for Source localization in wireless sensor networks", in the proceedings of International Conference on Communications, 1-5.

[42] K. Watfa, O. Mirza and J. Kawtharani “BA RC: A Battery Aware Reliable Clustering Algorithm for Wireless Sensor Networks", Journal of Computer Networks \& Applications, 32,6, 1183-1193.

[43] Muhammad Noman Riaz, Muhammad Nauman Qureshi, Dr Athar Mahboob, "Energy Efficient MAC Protocols for Wireless Sensor Networks : A Survey", International Journal of Scientific \& Engineering Research, 4(5):1859-1879, 2013.

\section{Authors' Profiles}

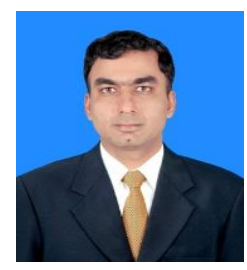

M Noman Riaz was born in September, 1982 at Karachi. He completed his B.S. in Electronic Engineering from Sir Syed University of Engineering \& Technology, Karachi in 2006. He then joined government owned organization as an engineering officer and since then worked in different capacities that include Simulator Maintenance Manager, Manager (Telecom and Computer Networks), Manager (Training \& Development), Senior Technical Manager (Air Field Electronics \& Communication). Besides having professional experience in engineering domain, he had been affiliated with National University of Sciences \& Technology, Islamabad as an Assistant Professor \& Training coordinator from April 2014 till October, 2017. He did his M.E. in Telecomm Engineering in 2010. Also, he completed his M.S. degrees in Project Management and Software Engineering in 2017 and 2018, respectively. Currently, he is pursuing PhD in Computer Software Engineering from National University of Computer \& Emerging Sciences, Islamabad, M.S. in Financial Engineering from World Quant University, Louisiana and MicroMasters in Data, Economics \& Development Policy from MITx.

How to cite this paper: Muhammad Noman Riaz, " Clustering Algorithms of Wireless Sensor Networks: A Survey", International Journal of Wireless and Microwave Technologies(IJWMT), Vol.8, No.4, pp. 40-53, 2018.DOI: $10.5815 /$ ijwmt.2018.04.03 